\title{
Modeling and control of HTPEMFC based Combined Heat and Power for confort control
}

\author{
Pau Martínez, Maria Serra and Ramon Costa-Castelló \\ Institut de Robòtica i Informàtica Industrial, CSIC-UPC \\ Llorens i Artigas 4-6 \\ 08028 Barcelona. \\ Email: martinezmolina.pau@gmail.com,maserra@iri.upc.edu,ramon.costa@upc.edu
}

\begin{abstract}
In this work the dynamic model of a domestic heating system is described. The heating system is based on a High Temperature PEM Fuel Cell. The model corresponds to a home placed in the city of Barcelona. The set of equations describing its behavior, the implementation in MATLAB/Simulink and some preliminary results for the control system are described.
\end{abstract}

\section{INTRODUCTION}

There is global concern about the harmful effects to the environment of the power generation methods based on fossil fuels, as well as uncertainty regarding the limited amount of these sources. Both things have caused the need to develop methods of energy production more sustainable and environmentally friendly [1].

Fuel cells, and Proton Exchange Membrane Fuel Cell (PEMFC) in particular, can cover this need for more sustainable energy systems. PEMFC are electrochemical devices based on the transformation of the chemical energy of hydrogen into electricity and heat. They are much more efficient than fossil fuels for the production of electricity. They also have an ecological benefit since the product obtained by the electrochemical PEMFC reaction is water.

Hydrogen generation is a problem by itself [2]. To make PEMFC a clean power generation system it is necessary to generate hydrogen in a clean manner such as using renewable energy, while if the production method is not based on sustainable primary sources, the final balance of the system will not be, in general, positive.

There exist different types of PEMFC. The most popular ones are Low-Temperature PEM Fuel Cells (LTPEMFC), which have been extensively developed and today can be easily produced with high power densities at relatively low cost. However, this type of FC have several handicaps such as the need of very pure hydrogen. Additionally, they work at relatively low temperatures so that there exist difficulties to take advantage of the heat generated also liquid water generation may occur inside the fuel cell, which lowers the efficiency of the cell seriously. These disadvantages lead research to develop High-Temperature PEM Fuel Cells (HTPEMFC). This type of PEMFC have a higher temperature operating range, usually between $120^{\circ}$ and $180^{\circ} \mathrm{C}$. Within this range, the heat generated can be transferred easily to a cooling device, thus creating a Combined Heat and Power generating system (CHP) [3] and increasing the efficiency considerably. HTPEMFC use a membrane which is able to operate without liquid water. In addition, all the water present in the stack comes into steam due to temperature, thus preventing floods. The problem of impurity intolerance is reduced, so it is possible to use less pure hydrogen, such as that obtained from a reforming process. But, HTPEMFC have some disadvantages, such as a slower start up and shorter durability due to degradation by temperature acid leach and agglomeration of catalyst.

CHP systems based on fuel cell systems are very attractive as sustainable energy methods. Countries like Japan and South Korea are leaders in the implementation of these systems for stationary domestic applications, and several countries of the western areas have planned implementation targets for the next years [4].

This work develops a model that has been designed to analyze the possibilities of a HTPEMFC as the power generation main element in a CHP system used to guarantee comfort in a domestic Building. The presented model is a control oriented and mainly focus in the thermal phenomena.

The paper is organized as follows, section II describes the architecture of the system under study, section III describes the heat exchange system, section IV describes the fuel cell models, section 6 describes the building model, section VI describes how the different elements have been integrated and finally section VII introduce some conclusions.

\section{SyStem ARCHITECTURE}

In this section most relevant components of the CHP system, and their interconnection, are qualitatively described (Figure 1). The core element of a PEMFC CHP system is the FC stack. To produce the reaction it must be feeded with $H_{2}$ which acts as fuel and $\mathrm{O}_{2}$ (section IV). Normally hydrogen is stored in pressurised tanks, and to regulate its flow a valve is usually sufficient. In contrast, oxygen is taken from the atmosphere and therefore it is necessary to incorporate a compressor to regulate its flow.

From the $\mathrm{H}_{2}$ and the $\mathrm{O}_{2}$ three elements are generated : water, electric power and heat. Water is a clean residue that must be removed from the fuel cell. To take profit from electric power usually power converters are required. Fuel cells are usually combined with electric energy storage systems to build hybrid systems (batteries or supercapacitors) [5] which 




Figure 1. Combined Heat and Power generation system components and interconnection.

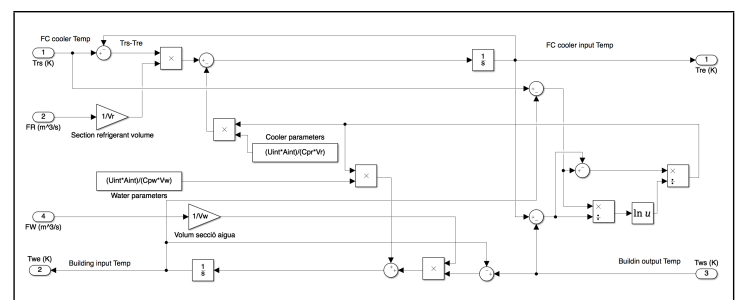

Figure 2. MATLAB/Simulink heat exchanger model implementation.

can feed electrical loads or inject energy to the distribution network.

Finally, the third element which is generated is heat. To take profit from it, it is necessary to introduce heat exchangers which extract the heat from the fuel cell and transfer it to the system to be heated, the building in our case. For technical and safety reasons usually this is done in two circuits, as shown in Figure 1. In order to heat the building different radiators are distributed throughout the building. The building exchanges heat with the exterior. External weather conditions act as a disturbance in the system.

\section{HEAT EXCHANGE SYSTEMS}

As sketched in Figure 1, the complete thermal system is composed by the PEMFC cooling system, a liquid-liquid heat exchanger and the house heating system (radiators). These three elements exchange heat through two different circuits. The liquid-liquid heat exchanger is in charge of the heat transfer from one circuit to the other

This heat exchange occurs in a concentric tube heat counterflow exchanger.The PEMFC cooling liquid will circulate in the internal tube while the house heating liquid will circulate in the external part. The fluids should be at a pressure between 5 and 6 atm, which is the usual pressure for heating systems. Additionally, the heating water temperature should increase around $20^{\circ}$ when going through it.

The heat exchanger parameters to be determined are four: the global heat transfer coefficient, $U_{i n t}$, the diameters of the tubes and the length of the exchanger. According to the literature [6] usual value for $U_{\text {int }}$ is $1150 \frac{\mathrm{W}}{\mathrm{m}^{2} \cdot \mathrm{K}}$. Diameters must be selected according to the flows and taking into account the velocities as well.

It is estimated that the coolant flow will go between $10^{-4}$ and $10^{-5} \frac{\mathrm{m}^{3}}{\mathrm{~s}}$ and the water will be to around $10^{-4}$ $\frac{\mathrm{m}^{3}}{\mathrm{~s}}$. Following literature recommendations of having liquid velocities between $10^{-2}$ and $10^{-3} \mathrm{~m} / \mathrm{s}$ in the first circuit [7] and estimating a flow around $10^{-4}$ and $10^{-5} \mathrm{~m}^{3} / \mathrm{s}$, the internal diameter is calculated to be $0.1 \mathrm{~m}$. If we assume manufacturers recommendations of having liquid velocities around $0.5 \mathrm{~m} / \mathrm{s}$ in the metallic tubes of the second circuit and estimating a flow of $10^{-4} \mathrm{~m}^{3} / \mathrm{s}$, the external diameter is calculated to be $0.12 \mathrm{~m}$.

The dynamic behavior of the heat exchanger is described by a model which uses as state variables the temperature of the water flow that exits the exchanger and heats the house, $T_{w e}$, and the temperature of the water flow that exits the exchanger and cools down the PEMFC, $T_{r e}$ :

$$
\begin{aligned}
\frac{d T_{r_{e}}}{d t}= & \frac{v_{r}}{V_{r}}\left(T_{r_{s}}-T_{r_{e}}\right) \\
& -\frac{U_{\text {int }} A_{\text {int }}}{C_{p_{r}} V_{r}}\left(\frac{\left(T_{r_{s}}-T_{w_{e}}\right)-\left(T_{r_{e}}-T_{w_{s}}\right)}{\ln \left(\frac{T_{r_{s}}-T_{w_{e}}}{T_{r_{e}}-T_{w_{s}}}\right)}\right) \\
\frac{d T_{w_{e}}}{d t}= & \frac{v_{w}}{V_{w}}\left(T_{w_{s}}-T_{w_{e}}\right) \\
& +\frac{U_{i n t} A_{i n t}}{C_{p_{w}} V_{w}}\left(\frac{\left(T_{r_{s}}-T_{w_{e}}\right)-\left(T_{r_{e}}-T_{w_{s}}\right)}{\ln \left(\frac{T_{r_{s}}-T_{w_{e}}}{T_{r_{e}}-T_{w_{s}}}\right)}\right)
\end{aligned}
$$

where $v_{r}$ and $v_{w}$ are the water flows of the first and the second circuits respectively; $V_{r}$ and $V_{w}$ are the volumes of the heat exchanger for the two liquids, respectively; $A_{\text {int }}$ is the heat exchange area and $C_{p r}$ is the water heat capacity.

Model inputs are the house heating system outlet water temperature, $T_{w s}$, and the PEMFC cooling system outlet temperature, $T_{r s}$. The model is based on temperature differences with half logarithmic output to calculate the temperatures of two liquids in a heat exchanger.

Figure 2 shows the MATLAB/Simulink implementation of the model.

\section{Fuel Cell System Models}

In the last years an important effort has been done to develop models for fuel cells [8], [9], [10], [11]. In the following a new model for a HTPEMFC is deduced. The model combines experimental data from a ZBT HTPEMFC and operational principles.

The developed model is based on an existing HTPEMFC by ZBT. Figure 4 shows its polarization curve. Among the recommendations of the manufacturer, the most important one is the maximum temperature of $453^{\circ} \mathrm{K}$. Above this temperature the HTPEMFC could be severely affected by degradation problems.

In PEMFC, two main electrochemical reactions are produced. The anode is fed with $\mathrm{H}_{2}$ and it is decomposed in protons and electrons:

$$
H_{2} \rightarrow 2 H^{+}+2 e^{-} \text {. }
$$




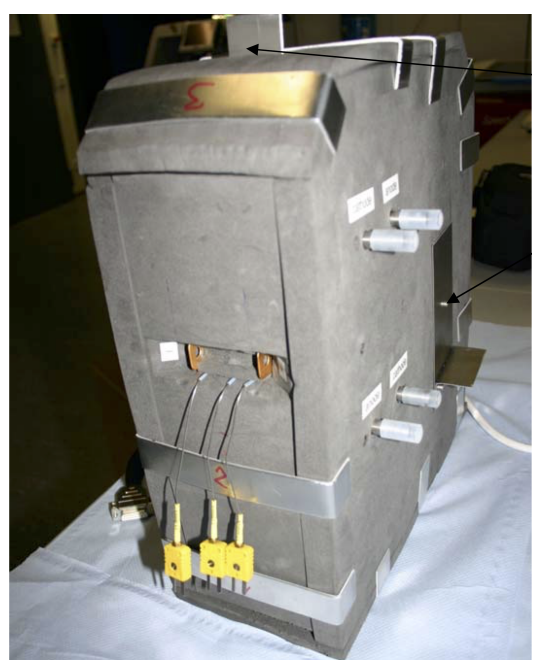

Figure 3. ZBT HTPEMFC Picture [reproduced from [12]].

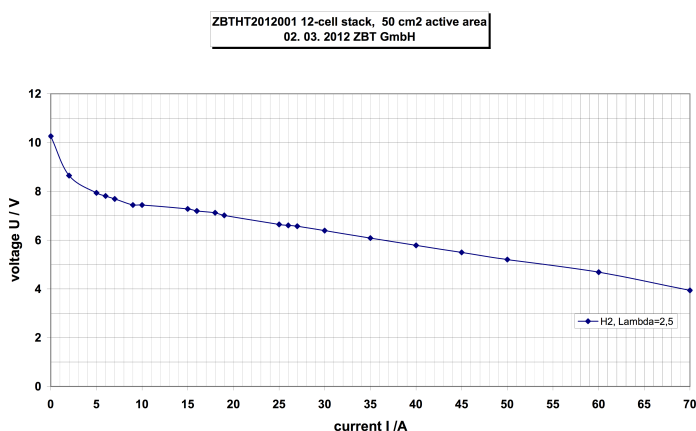

Figure 4. HTPEMFC polarization curve. The figure shows the steady-state relationship between voltage and current density for a ZBTHT fuel cell (12 cells stack) [reproduced from [12]].

While the cathode is fed with $\mathrm{O}_{2}$ and electrons and protons reaching from the anode are combined with $\mathrm{O}_{2}$ giving to :

$$
\frac{1}{2} \mathrm{O}_{2}+2 \mathrm{H}^{+}+2 e^{-} \rightarrow \mathrm{H}_{2} \mathrm{O} .
$$

The movement of electrons from the anode to the cathode generates electrical power. Additionally this reaction produces heat. The total energy generated by the reaction is known as the enthalpy of reaction, which can be calculated from the heats of formation of the reactants and products:

$$
\Delta H=\left(h_{f}\right)_{H_{2} O}-\left(h_{f}\right)_{H_{2}}-\frac{1}{2}\left(h_{f}\right)_{O_{2}}=\left(h_{f}\right)_{H_{2} O} .
$$

The energy generated is equal to the enthalpy of water formation as the formation enthalpy of a pure elements is zero.

The heat of formation of water takes two different values, depending on the final state of the water, which can be liquid or vapor. These values are $-286 \frac{\mathrm{kJ}}{\mathrm{mol}}$ when liquid water is obtained and $-241 \frac{\mathrm{kJ}}{\mathrm{mol}}$ when steam is obtained (both values at $25^{\circ} \mathrm{C}$ ) [13]. However, not all this energy can be directly transformed into electrical power, as in every chemical reaction, there is a portion of that energy that is used to generate

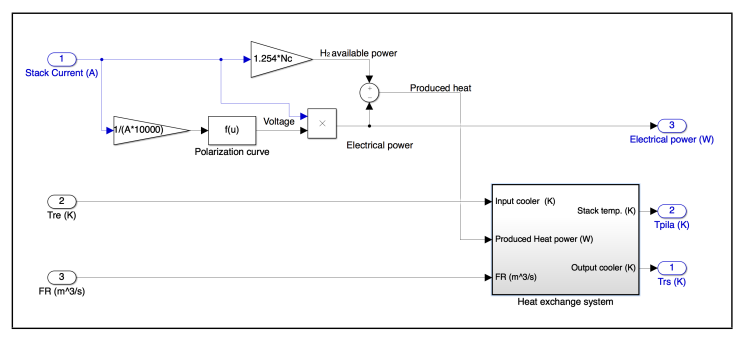

Figure 5. MATLAB/Simulink Fuel cell model implementation.

entropy. The part that can be transformed corresponds to the Gibbs free energy $(\Delta G)$ :

$$
\Delta G=\Delta H-T \Delta S .
$$

Where $T$ stands for the temperature and $\Delta S$ is the generated entropy. At $25^{\circ} \mathrm{C}$, only of $237 \frac{\mathrm{kJ}}{\mathrm{mol}}$ of the initial $286 \frac{\mathrm{kJ}}{\mathrm{mol}}$ can be transformed into electrical energy, the additional $49 \frac{\mathrm{kJ}}{\mathrm{mol}}$ are converted into heat (in case of steam, this value decreases to $229 \frac{\mathrm{kJ}}{\mathrm{mol}}$ [13]). As the Gibbs free energy is known, the potential of cell, $E$, can be calculated:

$$
E=\frac{\Delta G}{F \cdot n}
$$

where $n$ is the amount of exchanged electrons ( $n=2$ in the PEM Fuel Cell case) and $F=96485.3399 \frac{\mathrm{A} \cdot \mathrm{sec}}{\mathrm{mol}}$ is Faraday's constant, so the potential of the cell is $1.23 \mathrm{~V}$ with liquid water at $25^{\circ} \mathrm{C}$ or $1.19 \mathrm{~V}$ with steam water.

In practice the output voltage is decreased by several losses and, $U$ is computed as

$$
U=E-v_{a c t}-v_{o h m}-v_{c o n c}
$$

where $E$ is the open circuit voltage, previously introduced, $v_{\text {act }}$ are the activation losses, $v_{\text {ohm }}$ represent the ohmic losses and $v_{\text {conc }}$ are concentration over-voltages. These losses depend on many physical parameters being current the most significant one. Usually, the steady-state relationship between the output voltage and the current is measured experimentally (polarization curve). Figure 4 shows the polarization curve for ZBT HTPEMFC.

Usually, in order to increase the output voltage, FC are stacked. To form a stack $N_{c}$ cells are connected in series and the achieved electric voltage is $V_{\text {stack }}=U N_{c}$. For example, the polarization curve shown in Figure 4, corresponds to the output voltage of an stack of 12 cells.

The heat generated in the fuel cell stack, $P_{c}$, corresponds to the value obtained by subtracting the electric power, $P_{e}=$ $I_{\text {stack }} V_{\text {stack }}$, from the total power available in the fuel, $P_{\text {disp }}$ :

$$
P_{c}=P_{\text {disp }}-P_{e}
$$

where $P_{\text {disp }}=I_{\text {stack }} \cdot N_{c} \cdot 1.254$, so :

$$
P_{c}=I_{\text {stack }} \cdot N_{c} \cdot(1.254-U) \text {. }
$$

As the power required in our application will be considerably higher than the one obtained with this stack it is necessary to increase the number of cells. To avoid having a HTPEMFC 
with a very high number of cells also it is necessary to increase the active area up to $400 \mathrm{~cm}^{2}$ (corresponding to a cell of $20 \mathrm{~cm}$ square side). With this active area, and assuming a nominal current density of $500 \mathrm{~mA} / \mathrm{cm}^{2}$, the necessary number of cells to give a nominal required heat power of $13140 \mathrm{w}$ is $N_{c}=95$ (13140w is the power necessary to heat the house when the exterior temperature is $284^{\circ} \mathrm{K}$ and the desired interior temperature is $294^{\circ} \stackrel{\circ}{K}$ ).

It is important to emphasize that the current is proportional to the $\mathrm{H}_{2}$ consumption.

To appropriately operate the HTPEMFC it is necessary to regulate its temperature. To do this and take profit from the generated calorific power the Fuel cell system contains a heat exchanger. The heat power balance can be described as:

$$
P_{\text {input }}-P_{\text {output }}+P_{c}-P_{\text {stored }}=0 .
$$

where $P_{\text {input }}$ corresponds to the calorific power entering the heat exchanger, $P_{\text {ouput }}$ corresponds to the calorific power leaving the heat exchanger and $P_{\text {stored }}$ corresponds to the calorific power stored in the HTPEMFC. The power exchanged in the heat exchanger is

$$
P_{r}=P_{\text {output }}-P_{\text {input }}=U_{\text {cool }} \cdot A_{\text {cool }}\left(\frac{T_{r s}-T_{r e}}{\ln \frac{T_{F C}-T_{r e}}{T_{F C}-T_{r s}}}\right)
$$

where $U_{\text {cool }}=622.1 \frac{\mathrm{W}}{\mathrm{m}^{2} \dot{\mathrm{K}}^{-1}}$ is the global coefficient of heat transfer in the exchanger, $A_{\text {cool }}=1.2667$ corresponds to the contact acooling surface area, $T_{r e}$ corresponds to the cooler input temperature, $T_{T_{r} s}$ corresponds to the cooler output temperature and $T_{F C}$ is the Fuel Cell temperature. Similarly, this power exchange can be written as :

$$
P_{r}=v_{\text {cool }}^{\prime} \cdot C_{\text {cool }}\left(T_{r s}-T_{r e}\right)
$$

with $v_{c o o l}^{\prime}$ being the cooler volumetric flow and $C_{\text {cool }}=$ $4180000 \frac{\mathrm{J}}{\mathrm{K} \cdot \mathrm{m}^{3}}$ is the cooler (water) specific heat. Finally the Fuel Cell temperature can be computed as :

$$
M_{F C} C_{F C} \frac{d T_{F C}}{d t}=P_{\text {stored }}
$$

with $M_{F C}=50 \mathrm{Kg}$ being the HTPEMFC mass and $C_{F C}=$ $691 \frac{\mathrm{J}}{\mathrm{KKg}}$ being the fuel cell heat capacity.

From these equations it is possible to deduce the fuel cell model that will be used in this work :

$$
\begin{aligned}
T_{r s} & =T_{F C}+\left(T_{r s}-T_{F C}\right) e^{\frac{v_{\text {cool }}{ }^{-} \cdot C_{c o o l}}{c}} \\
\frac{d T_{F C}}{d t} & =\frac{P_{c}-U \cdot A_{r}\left(\frac{T_{r s}-T_{i n}}{\ln \frac{T_{F C}-T_{r e}}{T_{F C}-T_{r s}}}\right)}{M_{F C} C_{F C}}
\end{aligned}
$$

Figure 5 shows the model implementation in MATLAB/Simulink.

\section{Building Modeling}

Building modeling for control purposes is a challenging topic [14], [15], [16], [17]. In the following, basic concepts on building energy modeling will be introduced and based on that a simple model will be deduced. It is assumed that

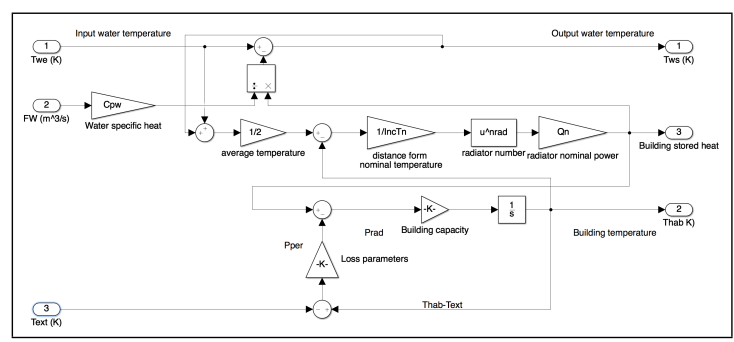

Figure 6. MATLAB/Simulink Building model implementation.

the model input is the secondary circuit water temperature while the output is the building temperature. It is assumed that the building can be considered a single room with a volume corresponding to the complete building, and the building is equipped with a radiator that corresponds to 15 single 10 elements radiators.

The thermic power balance is

$$
P_{\text {rad }}-P_{\text {per }}-P_{\text {stored }}=0
$$

where $P_{\text {rad }}$ correspond to the power irradiated by the radiators to the building, $P_{\text {stored }}$ is the power stored in the building and $P_{p e r}$ is the power exchanged with the exterior by the building. Irradiated power can be computed as:

$$
P_{\text {rad }}=Q_{n}\left(\frac{\frac{T_{w e}+T_{w s}}{2}-T_{\text {build }}}{\Delta T_{n}}\right)^{n}
$$

where $Q_{n}=89,4 \mathrm{~W}$ is the nominal power of one radiator and $\Delta T_{n}=40^{\circ}$ is the nominal radiator temperature increment. Irradiated power can also be computed as:

$$
P_{\text {rad }}=v_{w}^{\prime} C_{p w}\left(T_{w e}-T_{w s}\right)
$$

where $v_{w}^{\prime}=0.00016 \frac{\mathrm{m}^{3}}{\mathrm{~s}}, C_{p w}=4180000 \frac{\mathrm{J}}{\mathrm{Km}^{3}}$ is water specific heat, $T_{w e}$ is the input water temperature and $T_{w s}$ is the output water temperature.

The looses can be computed as:

$$
P_{\text {per }}=G_{\text {per }} V_{\text {build }}\left(T_{\text {build }}-T_{\text {ext }}\right)
$$

$G_{p e r}=3,65 \frac{W}{K m^{3}}$ is the volumetric looses coefficient, $V_{\text {build }}=360 \mathrm{~m}^{3}$ is the building volume, $T_{\text {ext }}$ is the exterior temperature and $T_{\text {build }}$ is the building temperature.

The power stored in the build can be computed as:

$$
P_{\text {stored }}=V_{\text {build }} C_{\text {build }} \frac{d T_{\text {build }}}{d t}
$$

where $C_{\text {build }}$ is the per volume thermal capacitance.

From previous equations it is possible to isolate $T_{w s}$ :

$$
\begin{aligned}
T_{w s} & =T_{w e}-\frac{Q_{n}\left(\frac{\frac{T_{w e}+T_{w s}}{2}-T_{h a b}}{\Delta T_{n}}\right)^{n}}{v_{w}^{\prime} C_{p w}} \\
\frac{d T_{\text {build }}}{d t} & =\frac{Q_{n}\left(\frac{\frac{T_{w e}+T_{w s}}{2}-T_{h a b}}{\Delta T_{n}}\right)^{n}-G_{p e r} V_{\text {build }}\left(T_{\text {build }}-T_{\text {ext }}\right)}{V_{\text {build }} C_{\text {build }}}
\end{aligned}
$$

which are the equations implemented in the simulator (Figure $6)$. 


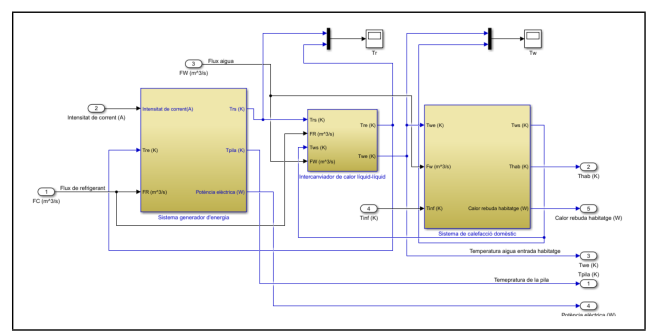

Figure 7. MATLAB/Simulink complete model implementation.

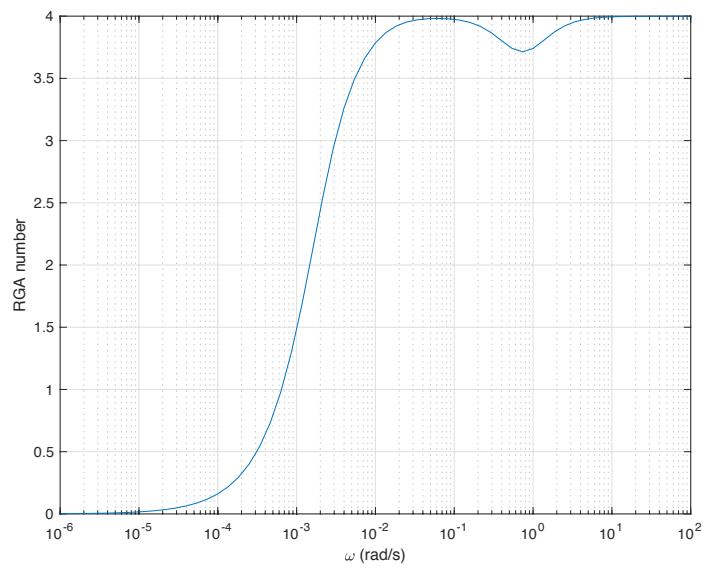

Figure 8. Linearized model RGA number evolution.

\section{Complete Model}

All previous models and their implementation have been combined to generate the complete comfort control model. Based on previous submodels, a MATLAB/Simulink model has been generated (Figure 7). Looking at the different equations that have been shown along the paper it can be seen it is high nonlinear system. This introduces complexity in the control system design and analysis. Due to this a linearized model $(\mathbf{A}, \mathbf{B}, \mathbf{C}, \mathbf{D})$ around most relevant equilibrium point, defined by $T_{h a b}^{*}=290^{\circ} \mathrm{K}, T_{F C}^{*}=433^{\circ} \mathrm{K}, T_{r e}^{*}=343.09^{\circ} \mathrm{K}$ and $T_{w e}^{*}=337.06^{\circ} \mathrm{K}$, has been obtained :

$$
\begin{gathered}
\mathbf{A}=\left[\begin{array}{cccc}
-0.01444 & 0.008022 & 0.005372 & 0.001043 \\
0.3561 & -0.5831 & 0.1367 & 0.09036 \\
0 & 1.939 \cdot 10^{8} & -9.507 \cdot 10^{8} & 0 \\
0.003861 & 0 & 0 & -0.003861
\end{array}\right] \\
\mathbf{B}=\left[\begin{array}{cc}
0 & 1.135 \cdot 10^{8} \\
0 & -4481 \\
0 & 0 \\
0.002102 & -1.153 \cdot 10^{8}
\end{array}\right], \mathbf{C}=\left[\begin{array}{ll}
0 & 0 \\
0 & 0 \\
1 & 0 \\
0 & 1
\end{array}\right]^{T}
\end{gathered}
$$

In this model, the FC current $\left(I_{\text {stack }}\right)$ and water flow $\left(v_{w}\right)$ increments are used as input while the FC temperature $\left(T_{\text {stack }}\right)$ and Building temperature $\left(T_{\text {build }}\right)$ increments are assumed as output,

Clearly, it is Multi-input Multi-output (MIMO) system [18]. A tool to characterize the coupling between inputs and outputs is the Relative Gain Analysis (RGA). Figure 8, shows the evolution of RGA number against frequency, as it can bee seen it is close to 0 in the low frequency range. This indicates that each output it is mainly explained in terms of one

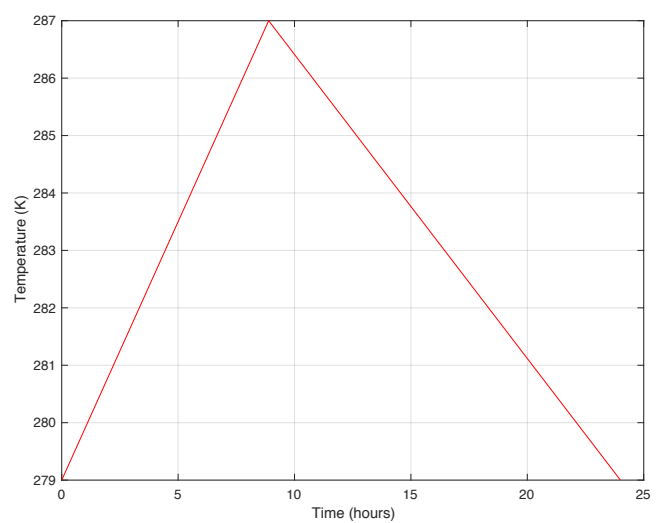

Figure 9. Ambient temperature evolution in the simulated scenario.

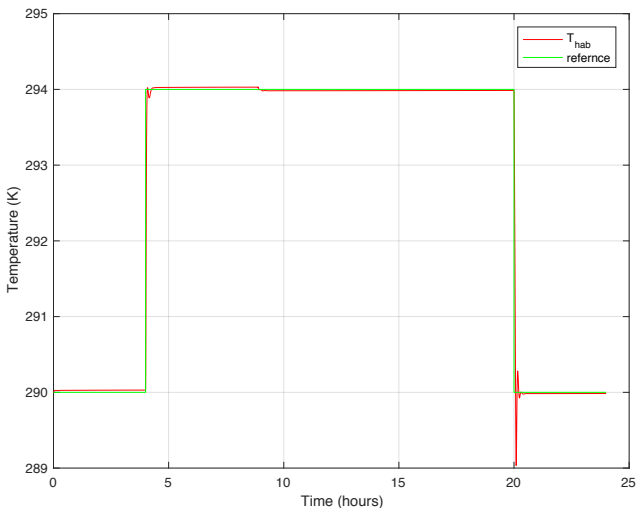

Figure 10. Building temperature and reference in the simulated scenario.

input, consequently the analysis suggest that it is possible to design a decoupled controller for each output variable. This controller structure is simpler and closed to engineering practice. Following this idea different PI controller have been tunned for the system,

This PI controllers have been validated using the nonlinear model. To analyze the system behavior, it has been defined and scenario where the ambient temperature follows the profile shown in figure 9. Additionally, its has been defined a constant reference $\left(433^{\circ} \mathrm{K}\right)$ for the $\mathrm{FC}$ temperature and a desired profile for the building temperature (see figure 10). As can bee seen in figure 10 and figure 11 , both the building temperature and the fuel cell temperature follow the desired reference in steadystate. Figure 12 and Figure 13 show the evolution of the fuel cell current and the water flow, the two variables used as control action. In both cases both variables are inside the reasonable limits. Although steady-state is the desired one, the achieved transient suggest that more sophisticated controller would be necessary in order to reduce the overshoots and to obtain a smoother control action.

\section{CONCLUSIONS}

This paper has been presented to develop a simple model based on basic principles of the comfort control system of a building using a fuel cell as the main energy source. The model, although simple, carefully describes the main phenomena and can be used for component sizing and allows 


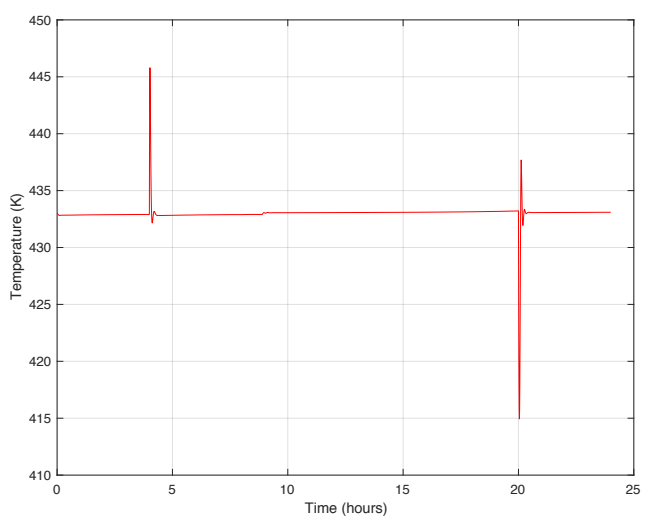

Figure 11. Fuel Cell temperature evolution in the simulated scenario.



Figure 12. Fuel Cell current evolution in the simulated scenario.

to develop simple simulations. Based on this model, a coupling between the different components has been performed. This analysis allows us to conclude that it is possible to design control systems for the different components in an uncoupled manner. The work has also presented a preliminary controller design and some simulations.

Currently, the authors are improving the model and the control system. Additionally, we are incorporating geolocation information that allows to take into account the influence of the concrete building localization in the comfort control.

\section{ACKNOWLEDGMENT}

This work was partially supported by the spanish Ministerio de Educación project DPI2015-69286-C3-2-R (MINECO/FEDER) and the catalan AGAUR project 2014 SGR 267.

\section{REFERENCES}

[1] "Dynamic model of a molten salt - gas heat recovery system for a hybrid renewable solar thermal power plant." Revista Iberoamericana de Automática e Informática Industrial RIAI, vol. 14, no. 1, pp. $70-$ 81, 2017.

[2] T. Lipman, "An overview of hydrogen production and storage systems with renewable hydrogen case studies," 2011.

[3] T. Sun, J. Lu, Z. Li, D. Lubkeman, and N. Lu, "Modeling Combined Heat and Power Systems for Microgrid Applications," IEEE Transactions on Smart Grid, vol. 3053, no. c, pp. 1-1, 2017. [Online]. Available: http://ieeexplore.iee.org/document/7815404/

[4] H. R. Ellamla, I. Staffell, P. Bujlo, B. G. Pollet, and S. Pasupathi, "Current status of fuel cell based combined heat and power systems for residential sector," Journal of Power Sources, vol. 293, pp. 312 - 328, 2015. [Online]. Available: http://www.sciencedirect.com/science/article/pii/S0378775315009313

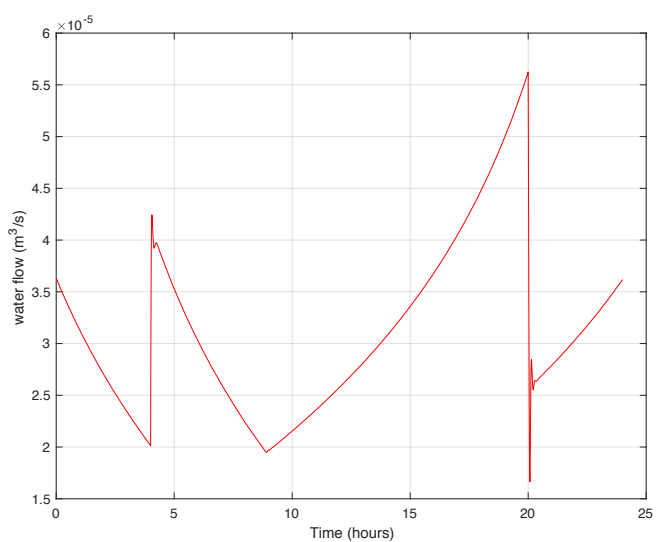

Figure 13. Water flow evolution in the simulated scenario.

[5] S. N. Motapon, L. A. Dessaint, and K. Al-Haddad, "A robust H2consumption-minimization-based energy management strategy for a fuel cell hybrid emergency power system of more electric aircraft," IEEE Transactions on Industrial Electronics, vol. 61, no. 11, pp. 6148-6156, 2014.

[6] (2017) Typical overall heat transfer coefficients. [Online]. Available: http://www.engineeringpage.com/technology/thermal/transfer.html

[7] S.-J. Wang, W.-W. Huo, Z.-Q. Zou, Y.-J. Qiao, and H. Yang, "Computational simulation and experimental evaluation on anodic flow field structures of micro direct methanol fuel cells," Applied Thermal Engineering, vol. 31, no. 14-15, pp. 2877 - 2884, 2011. [Online]. Available: http://www.sciencedirect.com/science/article/pii/S1359431111002651

[8] J. T. Pukrushpan, H. Peng, and A. G. Stefanopoulou, "Control-Oriented Modeling and Analysis for Automotive Fuel Cell Systems," Journal of Dynamic Systems, Measurement, and Control, vol. 126, no. 1, pp. 14-25, apr 2004. [Online]. Available: http://dx.doi.org/10.1115/1.1648308

[9] S. Strahl and R. Costa-Castelló, "Model-based analysis for the thermal management of open-cathode proton exchange membrane fuel cell systems concerning efficiency and stability," Journal of Process Control, vol. 47, pp. 201 - 212, 2016. [Online]. Available: http://www.sciencedirect.com/science/article/pii/S0959152416301184

[10] P. Martínez Molina, "Disseny i model dinàmic del sistema de calefacció d'un habitatge alimentat amb una pila pem d'alta temperatura," 2017, supervisor : Maria Serra Prat. [Online]. Available: http://hdl.handle.net/2117/101420

[11] E. Jannelli, M. Minutillo, and A. Perna, "Analyzing microcogeneration systems based on LT-PEMFC and HT-PEMFC by energy balances," Applied Energy, vol. 108, pp. 82-91, aug 2013. [Online]. Available: http://linkinghub.elsevier.com/retrieve/pii/S0306261913001864

[12] High Temperature Fuel Cell (HT-PEMFC) Stack (12 Cells). Users Manual, Zentrum für BrennstoffzellenTechnik. ZBT GmbH.

[13] F. Barbir, PEM Fuel Cells. Theory and Practice, second edition ed. Elsevier, 2012.

[14] T. Olofsson and T. M. I. Mahlia, "Modeling and simulation of the energy use in an occupied residential building in cold climate," Applied Energy, vol. 91, no. 1, pp. 432-438, 2012.

[15] D. Saelens, W. Parys, and R. Baetens, "Energy and comfort performance of thermally activated building systems including occupant behavior," Building and Environment, vol. 46, no. 4, pp. 835-848, 2011.

[16] H. F. Scherer, M. Pasamontes, J. L. Guzmán, J. D. Álvarez, E. Camponogara, and J. E. Normey-Rico, "Efficient building energy management using distributed model predictive control," Journal of Process Control, vol. 24, no. 6, pp. 740-749, 2014.

[17] R. Mascaró Palliser, R. Costa-Castelló, and J. D. Álvarez Hervás, "Una estrategia de control mediante observadores para la temperatura en edificio de oficinas." in Actas de las XXXVII Jornadas de Automática. Madrid: CEA, septiembre 2016, pp. 410-416, ISBN: 978-84-617-42981.

[18] S. Skogestad and I. Postlethwaite, Multivariable feedback control: Analysis and Design. Hoboken, US-NJ: John Wiley, 2005. 